\title{
ANALISIS RANTAI NILAI TEPUNG KELAPA PADA PT. TROPICA COCOPRIMA
}

\author{
Hamni Pisalemo \\ Nordy F. L. Waney \\ Lorraine W. Th. Sondak
}

\begin{abstract}
This study aims to determine the value of coconut flour at PT. Tropica Cocoprima. This research has been conducted at PT. Tropica Cocoprima and actors in its supply chain located at Jalan Trans Sulawesi Lelema Village Tumpaan Subdistrict of South Minahasa Regency. The type of data used is primary data and secondary data. Sources of data were obtained through interviews using questionnaires containing questions related to this study. The sampling method is Purvosive Sampling and the sample is PT. Tropica Cocoprima as focal firm and suppliers of raw materials as many as 5 suppliers as well as coconut farmers as much as 2 farmers taken from each supplier. The method of analysis used in this research is value chain analysis with cost and margin approach. Based on the research results can be concluded that the value chain of coconut flour at PT. Tropica Cocoprima There are several actors involved in the process of value creation. The actors involved are coconut farmers and suppliers who bring raw materials to PT. Tropica Cocoprima. The actors involved in the value chain of coconut flour each earn a margin that corresponds to the effort that has been done. Coconut flour value chain at PT. Tropica Cocoprima from one, two and three actors experienced value increase is Rp.195.000.000. Margin received by PT. Tropica Cocoprima amounting to Rp.12.277.822 then the supplier obtained a margin of Rp.6,675,000 and the farmer earned a margin of Rp.100.102.700.
\end{abstract}

Keywords: value chain analysis, coconut flour, PT. TROPICA COCOPRIMA.

\begin{abstract}
ABSTRAK
Penelitian ini bertujuan untuk mengetahui nilai tepung kelapa pada PT. Tropica Cocoprima. Penelitian ini telah dilaksanakan pada PT. Tropica Cocoprima dan pelaku dalam rantai pasoknya yang berlokasi di Jalan Trans Sulawesi Desa Lelema Kecamatan Tumpaan Kabupaten Minahasa Selatan. Jenis data yang digunakan adalah data primer dan data sekunder. Sumber data diperoleh melalui wawancara menggunakan kuesioner yang berisikan pertanyaan terkait dengan penelitian ini. Metode pengambilan sampel dilakukan secara Purvosive Sampling dan yang menjadi sampel adalah PT. Tropica Cocoprima sebagai focal firm dan pemasok bahan baku sebanyak 5 pemasok serta petani kelapa sebanyak 2 petani diambil dari masing-masing pemasok. Metode analisis yang digunakan dalam penelitian ini yaitu analisis rantai nilai dengan pendekatan biaya dan margin. Berdasarkan hasil penelitian dapat disimpulkan bahwa rantai nilai tepung kelapa pada PT. Tropica Cocoprima terdapat beberapa pelaku yang terlibat dalam proses penciptaan nilai. Pelaku yang terlibat diantaraya adalah petani kelapa kemudian pemasok yang membawa bahan baku pada PT. Tropica Cocoprima. Pelaku yang terlibat dalam rantai nilai tepung kelapa masing-masing memperoleh marjin yang sesuai dengan usaha yang telah dilakukan. Rantai nilai tepung kelapa pada PT. Tropica Cocoprima dari pelaku satu, dua dan tiga mengalami pertambahan nilai adalah Rp.195.000.000. Marjin yang diterima oleh PT. Tropica Cocoprima sebesar Rp.12.277.822 kemudian pemasok memperoleh marjin sebesar Rp.6.675.000 dan petani memperoleh marjin sebesar Rp.100.102.700.
\end{abstract}

Kata kunci: analisis rantai nilai, tepung kelapa, PT. TROPICA COCOPRIMA. 


\section{PENDAHULUAN}

\section{Latar Belakang}

Kelapa merupakan tanaman perkebunan yang cukup besar kontribusinya terhadap perekonomian Indonesia. Perkebunan kelapa memiliki luasan kedua terbesar di Indonesia setelah perkebunan kelapa sawit (Hani, 2007). Provinsi Sulawesi Utara merupakan Daerah penghasil kelapa terbesar kedua di Indonesia setelah Riau. Sulawesi Utara memiliki luas areal tanaman kelapa seluas 277.357,32 Ha.

Produksi tanaman kelapa di Sulut sebesar 264.607,92 ton per tahun (BPS Sulut, 2016). Daya saing produk kelapa pada saat ini terletak pada industri hilirnya (Piri, 2016). Nilai tambah yang tercipta dari produk hilir jauh lebih besar dari produk primernya. Tepung kelapa merupakan salah satu produk hilir kelapa yang potensial dan berdaya saing tinggi (Anis, 2017). Tepung kelapa ini dapat digunakan sebagai bahan makanan.

Sulawesi Utara merupakan salah satu Provinsi penghasil tepung kelapa di Indonesia. Tepung kelapa merupakan salah satu komoditi utama ekspor di Sulut. Permintaan tepung kelapa asal Sulawesi Utara lebih tinggi dibandingkan provinsi penghasil tepung kelapa lainnya. Sulawesi Utara mengekspor hingga ribuan ton tepung kelapa ke berbagai Negara di Eropa maupun Asia setiap tahun, sehingga mampu menghasilkan devisa bagi Negara. Tepung kelapa banyak dibutuhkan oleh industri makanan untuk dipakai sebagai salah satu bahan baku.

PT. Tropica cocoprima merupakan satu dari 9 perusahaan tepung kelapa di Sulawesi Utara. PT. Tropica cocoprima berdiri sejak tahun 1997 dan berkomitmen untuk terus meningkatkan kualitas produk agar dapat bersaing dengan perusahaan tepung kelapa lainnya. Saluran pemasaran dari produsen sampai ke konsumen sangat panjang dan melibatkan banyak pihak yang mengambil margin usaha yang lebih besar dibandingkan dengan pihak lain. Maka untuk melihat nilai dari tepung kelapa adalah dengan cara menganalisis rantai nilai tepung kelapa melalui pendekatan biaya dan margin.

\section{Rumusan Masalah}

Berdasarkan latar belakang, yang menjadi rumusan masalah dalam penelitian ini yaitu berapa besar nilai produk tepung kelapa pada PT. Tropica Cocoprima.

\section{Tujuan Penelitian}

Tujuan dari penelitian ini yaitu menganalisis Rantai Nilai Tepung Kelapa Pada PT. Tropica cocoprima, melalui pendekatan biaya dan margin.

\section{Manfaat Penelitian}

Manfaat penelitian ini yaitu untuk menambah pengetahuan bagi penulis, dan diharapkan dapat memberikan informasi kepada perusahaan dan masyarakat, tentang seperti apa rantai nilai tepung kelapa dan juga diharapkan dapat menjadi bahan referensi untuk penelitian selanjutnya, khususnya yang mengambil tema "Rantai Nilai Tepung Kelapa".

\section{METODOLOGI PENELITIAN}

\section{Waktu dan Tempat Penelitian}

Penelitian ini telah dilaksanakan pada PT. Tropica cocoprima dan pelaku dalam rantai pasoknya yang berlokasi di Jl. Raya Trans Sulawesi Desa Lelema Kecamatan Tumpaan Kabupaten Minahasa Selatan Provinsi Sulawesi Utara, selama 3 bulan.

\section{Jenis dan Sumber Data}

Jenis dan sumber data yang digunakan dalam penelitian ini adalah data primer dan data sekunder. Data primer diperoleh melalui wawancara dengan menggunakan kuesioner yang berisikan pertanyaan pada responden untuk mendapatkan jawaban, tanggapan, dan informasi yang diperlukan. Data sekunder diperoleh dari instansi atau lembaga terkait dengan penelitian ini.

\section{Metode Pengambilan Sampel}

Metode Pengambilan sampel dilakukan secara Purposive Sampling Yang menjadi sampel adalah: 
a. PT. Tropica cocoprima sebagai "focal firm" dalam rantai suplai produk tepung kelapa yang menjadi fokus penelitian

b. Pemasok bahan baku kelapa (supplier) sebanyak 5 pemasok

c. Petani kelapa sebanyak 2 petani diambil dari masing-masing pemasok.

\section{Konsepsi Pengukuran Variabel}

A. Gambaran Umum Responden

1. Umur, ditanyakan dengan satuan tahun

2. Jumlah tanggungan keluarga, ditanyakan dalam jumlah orang

3. Tingkat pendidikan, diukur menurut tingkatan pendidikan formal yang ditamatkan

4. Lamanya berusaha berdagang dan bertani kelapa

B. Variabel Pokok

1. Perusahaan (PT. Tropica Cocoprima)

- Harga beli kelapa butir (Rp/Kg)

- Produksi tepung kelapa adalah jumlah produksi dihitung dalam satu kali produksi $(\mathrm{Kg})$

- Proses produksi adalah aktifitas yang dilakukan mulai dari penerimaan bahan baku sampai pengepakan produk tepung kelapa

- Tenaga kerja adalah jumlah tenaga kerja yang digunakan dalam 1 kali proses produksi (HOK)

- Biaya adalah besarnya Biaya yang dikeluarkan (Rp)

- Harga jual produk tepung kelapa $(\mathrm{Rp} / \mathrm{Kg})$

2. Pemasok (supplier) bahan baku kelapa butir

- Harga beli kelapa butir $(\mathrm{Rp} / \mathrm{Kg})$

- Biaya adalah besarnya biaya yang dikeluarkan dalam proses pengangkutan $(\mathrm{Rp})$

- Harga jual kelapa butir $(\mathrm{Rp} / \mathrm{Kg})$

3. Petani kelapa

- Harga jual kelapa butir ( $\mathrm{Rp} / \mathrm{Kg})$

\section{Metode Analisis Data}

Data yang dikumpulkan akan dianalisis dengan analisis rantai nilai menggunakan alat kuantitatif melalui pendekatan biaya dan margin.

\section{HASIL DAN PEMBAHASAN}

\section{Deskripsi Umum Perusahaan}

PT. Tropica cocoprima adalah salah satu perusahaan yang memproduksi tepung kelapa di Sulawesi utara. PT. Tropica cocoprima berdiri sejak tahun 1997 dan mulai beroperasi pada tahun 1998. PT. Tropica cocoprima memiliki 252 tenaga kerja, terbagi atas tenaga kerja kantor dan tenaga kerja bagian produksi dengan jam kerja yang terdiri dari 2 shift. Shift I jam 07.00-15.00, shift II jam 15.00-11.00. Kapasitas produksi PT. Tropica cocoprima adalah 275 ton perbulan. PT. Tropica cocoprima berkomitmen untuk terus memproduksi dan memasok produk yang berkualitas serta aman untuk dikonsumsi. PT. Tropica Cocoprima menetapkan standar mutu bahan baku kelapa pada pemasok antara lain, jenis kelapa yaitu kelapa dalam, dengan berat 9-10 ons per butir, tidak pecah/cacat, kemudian gudang penyimpanan harus jauh dari area pertambangan dan kandang hewan.

Lokasi pabrik PT. Tropica cocoprima terletak di jalan Trans Sulawesi Desa Lelema Kecamatan Tumpaan Kabupaten Minahasa Selatan. Kantor Pusat PT. Tropica cocoprima yang menangani bagian marketing terletak di jalan Balai Kota No. 12 Manado. Negara tujuan ekspor tepung kelapa PT. Tropica cocoprima adalah Angola, Australia, Belgium, Egypt, Germany, Hungary, India, Japan, Korea, Malaysia, Netherlands, Poland, Russia, Saudi Arabia, South Africa, Singapore, Srilangka, Turkey, Uni Arab Emirates, United States of America.

\section{Karakteristik Responden}

\section{Umur Responden}

\begin{tabular}{cccccc}
\multicolumn{2}{l}{ Tabel 1. Jumlah Responden Menurut Umur } \\
\hline \multirow{2}{*}{ No. } & \multirow{2}{*}{ Umur (Tahun) } & \multicolumn{2}{c}{ Jumlah Responden (Orang) } & \multicolumn{2}{c}{ Persentase (\%) } \\
\cline { 3 - 6 } & & Pemasok & Petani Kelapa & Pemasok & Petani \\
\hline 1 & $41-50$ & 1 & 1 & 20 & 10 \\
2 & $51-60$ & 1 & 5 & 20 & 50 \\
3 & $61-70$ & 2 & 3 & 40 & 30 \\
4 & $71-80$ & 1 & 1 & 20 & 10 \\
\hline \multicolumn{7}{c}{ Jumlah } & 5 & 10 & $100 \%$ & $100 \%$ \\
\hline \multicolumn{2}{c}{ Rata-rata } & 62 tahun & 58 tahun & & \\
\hline
\end{tabular}

Tabel 1 menunjukkan jumlah responden pemasok diamana responden berusia 41-50 tahun, 51-60 tahun dan 71-80 tahun masing- 
masing berjumlah 1 orang dan responden berusia 61-70 tahun berjumlah 2 orang. Responden petani berusia 41-50 tahun sama dengan responden berusia 71-80 tahun yaitu masing-masing berjumlah 1 orang. Responden petani berusia 51-60 tahun berjumlah 5 orang dan responden petani berusia $61-70$ berjumlah 3 orang.

\section{Tingkat Pendidikan}

\begin{tabular}{llcccc}
\multicolumn{2}{c}{ Tabel 2. Jumlah Responden Menurut Tingkat Pendidikan } \\
\hline \multirow{2}{*}{ No. } & \multirow{2}{*}{ Tingkat Pendidikan } & $\begin{array}{c}\text { Jumlah Responden } \\
\text { (Orang) }\end{array}$ & \multicolumn{2}{c}{ Persentase (\%) } \\
\cline { 3 - 6 } & & $\begin{array}{c}\text { Pemasok } \\
\text { Petani kelapa }\end{array}$ & Pemasok & Petani \\
\hline 1 & SD & 1 & 4 & 20 & 40 \\
2 & SLTP & - & 4 & - & 40 \\
3 & SLTA & 3 & 2 & 60 & 20 \\
4 & S1 & 1 & - & 20 & - \\
\hline & Jumlah & 5 & 10 & $100 \%$ & $100 \%$ \\
\hline
\end{tabular}

Tabel 2 menunjukkan tingkat pendidikan responden pemasok, dimana responden terbanyak yaitu tamat SLTA dengan presentase 60 persen kemudian SD dengan presentase 20 persen dan S1 dengan presentase 20 persen. Jumlah responden petani tamat SLTP sama dengan jumlah petani tamat SD yaitu dengan presentase masing-masing 40 persen dan responden tamat SLTA dengan presentase 20 persen. Tingkat pendidikan pemasok dan petani bervariasi.

\section{Lamanya Berusaha}

Tabel 3. Jumlah Responden Menurut Pengalaman Berusaha

\begin{tabular}{cccccc}
\hline \multirow{2}{*}{ No. } & $\begin{array}{c}\text { Lamanya Berusaha } \\
\text { (Tahun) }\end{array}$ & \multicolumn{2}{c}{ Jumlah Responden (Orang) } & \multicolumn{2}{c}{ Persentase (\%) } \\
\cline { 2 - 6 } & $5-10$ & 1 & 1 & 20 & 10 \\
\hline 1 & $11-20$ & 2 & - & 40 & - \\
2 & $21-30$ & 1 & 8 & 20 & 80 \\
3 & $31-40$ & 1 & 1 & 20 & 10 \\
4 & Jumlah & 5 & 10 & $100 \%$ & $100 \%$ \\
\hline \multicolumn{2}{l}{ Rata-rata } & 14 tahun & 26 tahun & & \\
\hline
\end{tabular}

Tabel 3 menujukkan tingkat lamanya berusaha responden pemasok, dimana responden berusaha 5-10 tahun, kemudian 2130 tahun dan 31-40 tahun masing-masing berjumlah 1 orang, kemudian 11-20 tahun berjumlah 2 orang. Responden petani berusaha paling banyak pada 21-30 tahun dengan presentase 80 persen kemudian kurang dari 10 tahun dengan presentase 10 persen dan 31-40 tahun dengan presentase 10 persen.

\section{Luas Lahan}

Tabel 4. Jumlah Responden Menurut Luas Lahan

\begin{tabular}{|c|c|c|c|c|c|}
\hline \multirow{2}{*}{ No. } & \multirow{2}{*}{ Luas Lahan $(\mathrm{Ha})$} & \multicolumn{2}{|c|}{ Jumlah Responden (Orang) } & \multicolumn{2}{|c|}{ Persentase (\%) } \\
\hline & & Pemasok & Petani Kelapa & Pemasok & Petani \\
\hline 1 & $1-5$ & - & 2 & - & 20 \\
\hline 2 & $6-10$ & - & 6 & - & 60 \\
\hline 3 & $11-20$ & - & 2 & - & 20 \\
\hline \multicolumn{2}{|r|}{ Jumlah } & \multicolumn{2}{|r|}{10} & & $100 \%$ \\
\hline & Rata-rata & & $10 \mathrm{Ha}$ & & \\
\hline
\end{tabular}

Tabel 4 menunjukkan bahwa lahan yang digunakan untuk perkebunan kelapa oleh responden petani kelapa rata-rata 10 hektar dan untuk ukuran perkebunan luas lahan rata-rata yang digunakan responden petani kelapa terhitung cukup besar. dan untuk pemasok tidak ada ukuran lahan.

\section{Status Penguasaan Lahan}

Berdasarkan hasil penelitian, lahan yang diusahakan oleh petani kelapa rata-rata adalah lahan milik sendiri.

\section{Pemetaan Proses Inti dalam Rantai Nilai Tepung Kelapa}

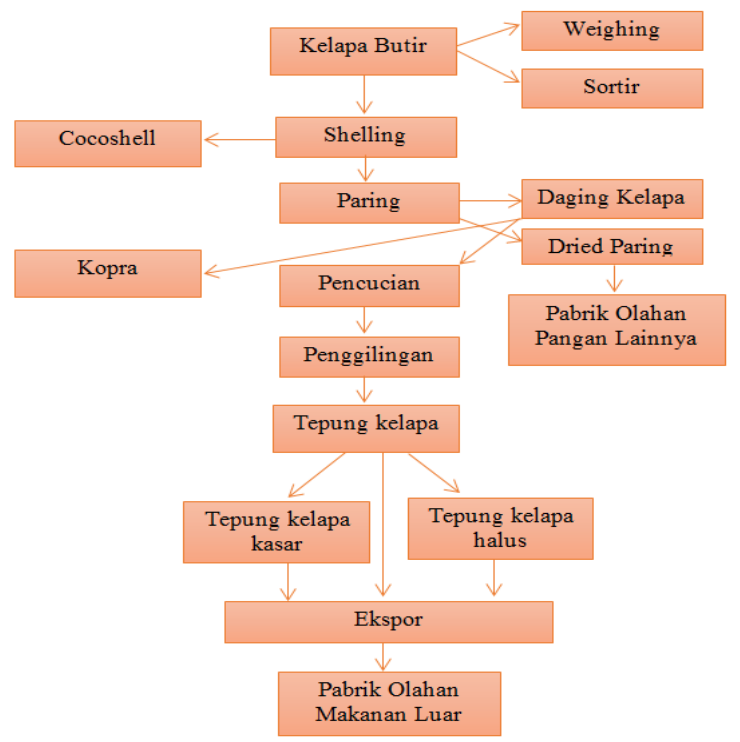

Gambar 1. Pemetaan proses inti dalam rantai nilai tepung kelapa

\section{Identifikasi Pelaku Rantai Nilai Tepung Kelapa}

Menurut Kaplinsky dan Morris (2001) dalam Anonim (2012), analisis rantai nilai secara sistematis memetakan para pelaku yang berpartisipasi dalam produksi, distribusi, pemasaran, dan penjualan suatu produk atau berbagai produk tertentu. 


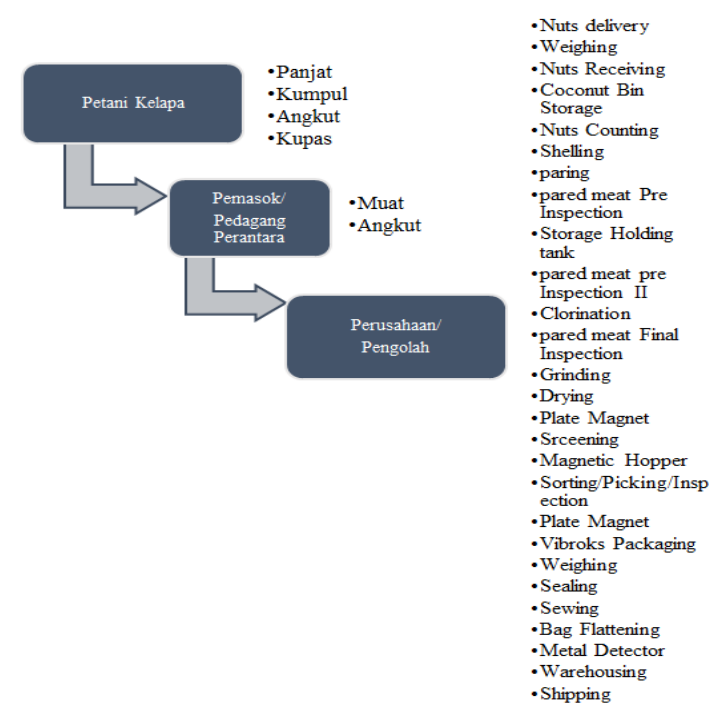

Gambar 2. Pemetaan Kegiatan Spesifik yang dilakukan oleh para Pelaku

\section{Petani Kelapa}

Petani kelapa merupakan produsen utama bahan baku pembuatan tepung kelapa pada PT. Tropica cocoprima. Petani kelapa berasal dari Klabat, Dimembe, dan Jalan sea. Petani menjual kelapa pada pemasok dengan harga Rp.21502200. PT. Tropica cocoprima sebagai perusahaan tepung kelapa, lebih mengutamakan bahan baku jenis kelapa dalam, karena bahan baku dari jenis kelapa dalam dinilai dapat memberikan kualitas tepung yang bermutu. Petani memberikan informasi ke supplier apabila kelapa sudah siap untuk diangkut.

\section{Supplier/Pemasok Bahan Baku}

Supplier bahan baku membeli kelapa pada petani disekitar wilayahnya, dengan harga sekitar Rp.2150-2200/kg. Bahan baku dipasok setiap hari dan kuantitas bahan baku tegantung pada kemampuan masing-masing supplier. Supplier melakukan pendistribusian ke perusahaan setelah bahan baku mencapai standar 5-7 ton atau lebih, dengan menggunakan kendaraan milik perusahaan.

\section{Perusahaan}

PT. Tropica cocoprima memasok bahan baku kelapa dari berbagai daerah yang tersebar di Sulawesi Utara, seperti Minahasa Utara, Minahasa Induk dan Bolaang Mongondow. PT. Tropica cocoprima melakukan wawancara terlebih dahulu untuk mengetahui informasi tentang supplier, seperti keadaan lokasi dan gudang untuk bahan baku, kapasitas kelapa yang dapat dikirim pemasok, serta orang-orang yang dipekerjakan. Perusahaan juga memberikan informasi tentang standar kualitas kelapa yang digunakan untuk produksi, seperti berat standar kelapa 8-10 ons perbutir, buah kelapa tidak muda, tidak busuk dan tidak pecah. Perusahaan membeli bahan baku pada pemasok dengan harga Rp.2.300-2.500.

Perusahaan melakukan pemesanan bahan baku setiap hari kepada beberapa supplier yang mempunyai persediaan bahan baku untuk memenuhi kebutuhan produksi tepung kelapa sebesar 65 ton per hari. Perusahaan membentuk tim dalam rangka mengunjungi supplier satu tahun sekali untuk menjaga relasi yang baik.

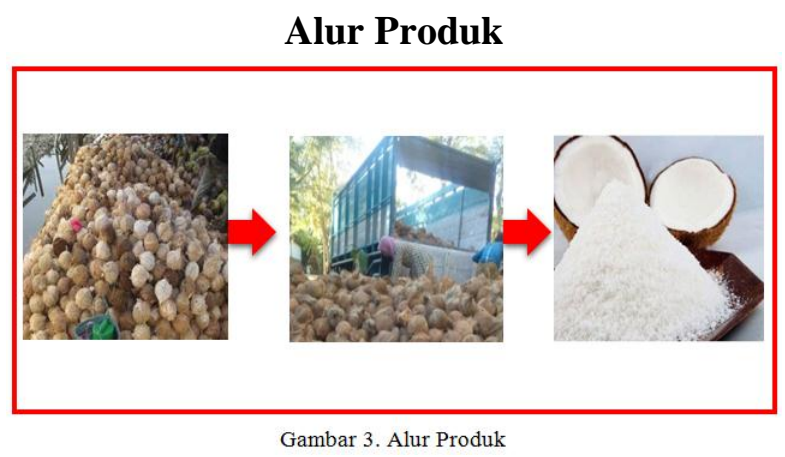

\section{Struktur Rantai Nilai Tepung Kelapa}

Berdasarkan hasil penelitian, alur produk rantai nilai tepung kelapa dari petani masih berbentuk kelapa butir tanpa sabut, kemudian pemasok melakukan pendistribusian kepada perusahaan sebagai pengolah. Kemudian perusahaan mengolah bahan baku menjadi tepung kelapa yang siap untuk diekspor. Dapat dilihat pada Gambar 4

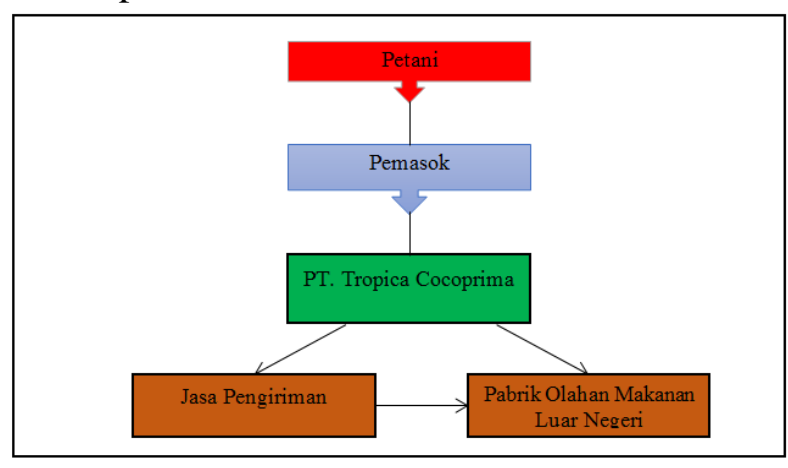

Gambar 4. Struktur Rantai Nilai Tepung Kelapa 


\section{Menganalisis Biaya dan Margin pada Pelaku Rantai Nilai}

Menurut Kaplinsky dan Morris (2001) dalam Anonim (2012), melalui analisis margin dan laba di dalam rantai nilai, dapat dilihat siapa saja yang memperoleh manfaat dari partisipasi dalam rantai nilai dan pelaku mana yang dapat memperoleh manfaat dari dukungan atau pengorganisasian yang lebih baik.

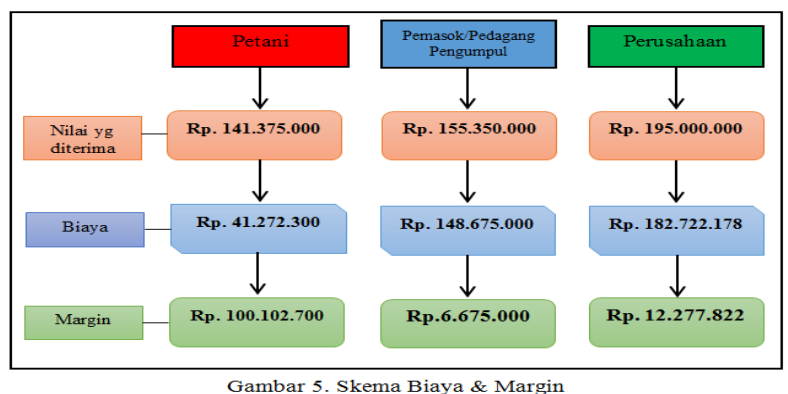

Gambar 5. Memperlihatkan nilai yang diterima pada setiap pelaku serta biaya yang dikeluarkan pada setiap pelaku dan juga memperlihatkan margin atau selisih antara nilai yang diterima setelah dikurangi biaya. Perhitungan biaya dan marjin dilakukan berdasarkan jumlah bahan baku yang sama yang diproduksi oleh perusahaan dalam satu kali proses produksi yaitu $65.000 \mathrm{~kg}$ bahan baku kelapa.

\section{KESIMPULAN DAN SARAN}

\section{Kesimpulan}

Hasil penelitian menunjukkan bahwa nilai tepung kelapa pada PT. Tropica Cocoprima dalam satu kali proses produksi adalah Rp.195.000.000. Marjin yang diterima oleh PT. Tropica Cocoprima sebesar Rp.12.277.822 kemudian pemasok memperoleh marjin sebesar Rp.6.675.000 dan petani memperoleh marjin sebesar Rp.100.102.700.

\section{Saran}

Berdasarkan kesimpulan penelitian, maka penulis merekomendasikan saran yaitu untuk meningkatkan nilai produk tepung kelapa pada PT. Tropica Cocoprima yaitu dengan memperhatikan kualitas bahan baku yang dipasok agar tidak cacat sehingga dapat menghasilkan Deciccated Coconut yang bermutu tinggi.

\section{DAFTAR PUSTAKA}

Anonim. 2012. Membuat Rantai Nilai Lebih Berpihak pada Kaum Miskin. Monograph. Australian Centre for International Agricultural Research. (ACIAR). Canberra.

Anis Ch., A. E. Loho., \& G. A. Rumagit. 2017. Analisis Pengelolaan Rantai Pasok Tepung Kelapa Pada PT. XYZ di Sulawesi Utara. Jurnal. Agrisosioekonomi, Volume 13. Halaman 8188.

Badan Pusat Statistik. 2016. Produksi Tanaman Kelapa di Sulawesi Utara. Badan Pusat Statistik Sulawesi utara. Manado.

Hani. 2007. Analisis Rantai Pasokan Buah Kelapa Studi Kasus Rantai Pasokan Buah Kelapa di Kotamadya Bogor. Skripsi tidak diterbitkan. Institut Pertanian Bogor. Bogor. 